\title{
Design method of the pinned external integrated buckling-restrained braces with extended core. Part II: finite element numerical verification"
}

\author{
Zi-qin JIANG ${ }^{\dagger 1}$, Yan-lin GUO ${ }^{2}$, Jing-zhong TONG ${ }^{2}$, Xing YUAN ${ }^{2}$ \\ ( ${ }^{1}$ College of Architecture and Civil Engineering, Beijing University of Technology, Beijing 100124, China) \\ ( ${ }^{2}$ Department of Civil Engineering, Tsinghua University, Beijing 100084, China) \\ †E-mail: jzqbj2010@163.com
}

Received Oct. 25, 2014; Revision accepted June 17, 2015; Crosschecked Sept. 26, 2015

\begin{abstract}
The theoretical derivation from Part I (Jiang et al., 2015) has obtained the core contact force and the bending moment distribution of the external member in the single-wave core deformation mode. In addition, the design criteria of the external member and the strengthened core region (SCR) have also been obtained based on the understanding of the mechanical characteristics of the buckling-restrained brace (BRB). Based on the theoretical results from Part I, this study conducts the corresponding finite element (FE) numerical verification, and the BRB parameter analysis is also performed when the core deforms as a single-wave deformation. The influence of nine parameters on the core contact force and the external member stress is investigated. These parameters include the flexural rigidity of external member, the initial imperfection of external member, the core thickness and its width-to-thickness ratio, the pinned connector length, the external member length, the length of restrained strengthened core region with uniform section and the height of the wing-plate of the SCR, as well as the gap between the core and the external member. Lastly, the 12 examples of BRBs that are designed according to the proposed design criteria are analyzed using FE simulation, and the reliability of the theoretical derivation is also verified.
\end{abstract}

Key words: External integrated buckling-restrained brace (BRB), Core single-wave overall deformation, Contact force distribution, Strengthened core region (SCR), Design criteria, Refined finite element doi: 10.1631 jzus.A1400326

Document code: A

CLC number: TU391

\section{Introduction}

Buckling-restrained braces (BRBs) have been widely applied for new and retrofitting of existing structures (Black et al., 2004; Qiang, 2005; Tremblay et al., 2006; Di Sarno and Manfredi, 2010; 2012; Di Sarno et al., 2013) because they not only behave as a brace but also possess good hysteretic performance. The BRB is fixed (Iwata and Murai, 2006; Tsai and Hsiao, 2008; Chou and Chen, 2010) or

\footnotetext{
* Project supported by the National Natural Science Foundation of China (No. 51178243)

(D) ORCID: Zi-qin JIANG, http://orcid.org/0000-0001-9613-3972

(C) Zhejiang University and Springer-Verlag Berlin Heidelberg 2015
}

pinned to a frame in high rise buildings, and the pinned BRBs (Fahnestock et al., 2007; Wigle and Fahnestock, 2010; Zhao et al., 2012b) are the focus of this study.

For the pinned BRBs, to ensure that the yield region of a single core plate is well restrained by the external member, it is reinforced before the core comes out of the external member (Chen et al., 2001; Qiang, 2005; Iwata and Murai, 2006). Thus, there are three distinct failure modes of pinned BRBs: (1) Bending failure around the extended core region due to its insufficient load-bending capacity (Zhao et al., 2011); (2) Overall buckling failure due to deficient external member bending stiffness (Ju et al., 2009; Zhao et al., 2012a); and (3) Local press failure at the 
external member end due to significant stiffness weakening or immense contact force. This study mainly focuses on the first two failure modes, and the third is not included in this study as it is a detailed construction issue of the external member end.

For a pinned BRB with a single core flat plate, the core deforms as the single-wave overall deformation mode (Fig. 1). Based on a hypothetical core member's contact force distribution mode, Part I has theoretically derived the core contact force and the bending moment distribution of the external member (Jiang et al., 2015). In addition, the design criteria of the external member and the strengthened core region (SCR) have been formulated, so as to prevent the pinned BRBs from the two failure modes mentioned above.

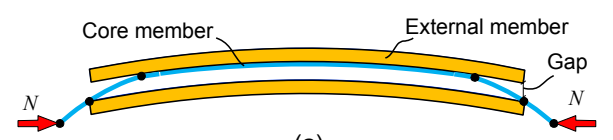

(a)

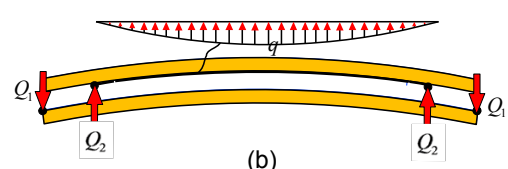

Fig. 1 A typical deformation modes of core member (a) Core single-wave overall deformation; (b) Force analysis on external member

$N$ is the core axial load, $q$ is the distribution load acting on the core contact region, $Q_{1}$ is the concentrated contact force between the core and the external restraining member ends when $\mathrm{BRB}$ has single-wave overall deformation, and $Q_{2}$ is the concentrated contact force between the core and the external restraining member when BRB has single-wave overall deformation

As a core of a BRB yields, the equations derived from the elastic theory are inaccurate. In addition, the contact position between the core and external restraining member also changes with the core axial strain increasing, thus the equation derived needs finite element $(\mathrm{FE})$ analysis verification. Thus, FE numerical analysis is used to verify and amend the assumptions in the theoretical derivation and results. Moreover, the parameter analysis is carried out only in the condition of a core single-wave deformation; the influence of nine parameters on the core contact force and the external restraining member stress is investigated; the corresponding axial load- bearing capacity is checked by 12 examples of BRBs and the reliability of the theoretical derivation is verified.

\section{Theoretically derived results}

\subsection{Stress state of the pinned BRBs with core single-wave overall deformation}

In Part I (Jiang et al., 2015), the following assumptions are made in a simplified model: the initial geometric imperfection of the core and the external member follow a sinusoidal pattern and the critical state when the core and the external member end start to have two-point-contact is deemed to be the initial state of the BRB (Fig. 2). The distributed contact force appears as a sinusoidal pattern (Nagao and Takahashi, 1991; Inoue and Sawaisumi, 1992) when the core has single-wave deformation, and the bending moment of the core contact region is zero.

Based upon the above assumptions, the force equilibrium equations of the extended strengthened core region (ESCR) and the restrained strengthened core region (RSCR) are established. By employing the deformation compatibility relationship between the core and the external member at some contact points, the maximum bending moment on the extended core region $M_{\text {ec }}$ (Eq. (1)), the maximum contact force on the core member $Q_{1}$ (Eq. (2)), the maximum bending moment on the external member $M_{\text {em,max }}$ (Eq. (3)), and the BRB's end rotation $\theta_{\mathrm{ec}}$ (Eq. (4)) are obtained:

$$
\begin{gathered}
M_{\mathrm{ec}}=c_{2} N L_{\mathrm{c}}, \\
Q_{1}=\left(w_{1}+c_{2} w_{2}\right) N, \\
M_{\mathrm{em}, \max }=Q_{1} L_{\mathrm{c}}+\frac{L_{\mathrm{y}}^{2}}{\pi^{2}} q_{0}, \\
\theta_{\mathrm{ec}}=\left(r_{1}+r_{2} k_{1}\right) \delta_{2}+r_{2} k_{2}\left(w_{1}+c_{2} w_{2}\right) / k,
\end{gathered}
$$

where $c_{2}, w_{1}, w_{2}, k_{1}, k_{2}, r_{1}$, and $r_{2}$ are calculation coefficients mentioned in Part I (Jiang et al., 2015); $k=\sqrt{N /\left(\eta_{1} E_{\mathrm{p}} I_{\mathrm{p}}\right)}$, where $E_{\mathrm{p}} I_{\mathrm{p}}$ is the elastic flexural rigidity of ESCR, and $\eta_{1}$ is SCR's rigidity reduction coefficient, the value of which is related to the core axial strain by considering the plasticity influence. $\delta_{2}$ is the deformation amplitude of the core member in 
the initial state, $q_{0}$ is the mid-span contact force distribution intensity, $L_{\mathrm{c}}$ is the horizontal distance between two contact points $c$ and $d$ of the core member end, $L_{\mathrm{y}}$ is the horizontal distance between two inner contact points in the middle of core member, and $N$ is the axial force acting on the core member.

Moreover, in Fig. 2, $\delta_{0}$ represents the initial imperfection amplitude of the external member, $g$ represents the lateral gap between the core and the external member, and $L_{\mathrm{BRB}}$ represents the distance between two pinned connectors of BRB. $L_{\mathrm{cm}}$ and $L_{\mathrm{em}}$ represent the lengths of core member and external restraining member, respectively, and $L_{0}$ is the length of a pinned connector. $L_{\mathrm{c} 10}, L_{\mathrm{c} 20}$, and $L_{\mathrm{c} 0}$ respectively are the length of RSCR with uniform section, variable section length, and the total length of the RSCR when a pinned BRB is in the initial state. $L_{\mathrm{p} 0}$ and $L_{\mathrm{y} 0}$ respectively denote the lengths of the ESCR and core flat-plate when the BRB is in the initial state. $L_{1}$ and $L_{2}$ respectively represent the distances between the contact points $d, c$ and the pinned connector, and $L_{3}$ represents the distance between the contact point $d$ and the core member end. $L_{\mathrm{p}}$ is the length of ESCR subjected to the given flexural moment.

\subsection{Design criteria of the BRB}

Based on the bending capacity of the external member, the design criteria for the external member of the pinned BRBs were deduced in Part I (Jiang et al., 2015). The value of the BRB's restraining ratio $\xi$ is

$$
\xi=\frac{\pi^{2} E_{\mathrm{b}} I_{\mathrm{b}}}{L_{\mathrm{BRB}}^{2} N_{\mathrm{y}}}
$$

and the minimal value of $\xi$ is

$$
\xi \geq[\xi]=\frac{w L_{\mathrm{y}}^{2}\left[W_{\mathrm{em}} f_{\mathrm{ey}}+\left(\pi^{2} / 8-1\right) Q_{1} L_{\mathrm{c}}\right]}{L_{\mathrm{BRB}}^{2}\left(W_{\mathrm{em}} f_{\mathrm{ey}}-w N_{\mathrm{y}} x_{1} \delta_{0}-Q_{1} L_{\mathrm{c}}\right)},
$$

where $E_{\mathrm{b}} I_{\mathrm{b}}$ represents the external restraining member's flexural rigidity, $N_{\mathrm{y}}$ represents the core yield load, $w$ is the core strength improvement coefficient in the plasticity stage, $W_{\mathrm{em}}$ is the elastic modulus of the section in the external restraining member to the outer fiber in the bending direction, and $f_{\text {ey }}$ is the yield stress of the external member steel.

In addition, the ESCR is a beam-column, and based on the plasticity theories (Chen, 2005), the design equation of ESCR is established as

$$
\left(\frac{N}{N_{\mathrm{p}, \mathrm{ec}}}\right)^{2}+\frac{M_{\mathrm{ec}}}{M_{\mathrm{p}, \mathrm{ec}}}<1.0,
$$

where $N_{\mathrm{p}, \mathrm{ec}}$ is the fully sectional yield force of the ESCR, and $M_{\mathrm{p}, \mathrm{ec}}$ is the fully sectional plasticity bending moment of the ESCR.

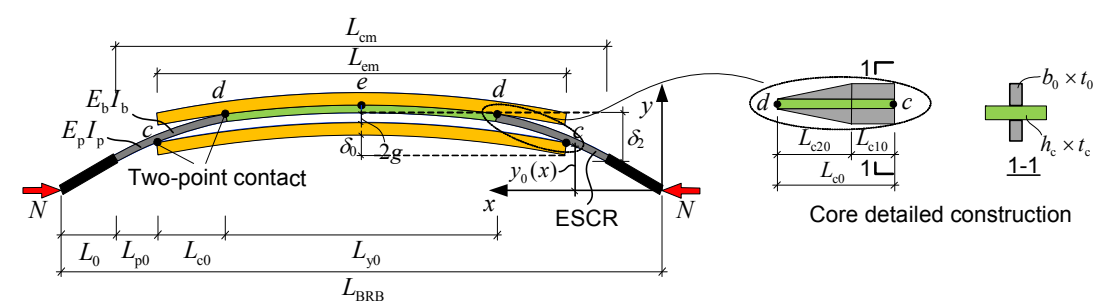

(a)

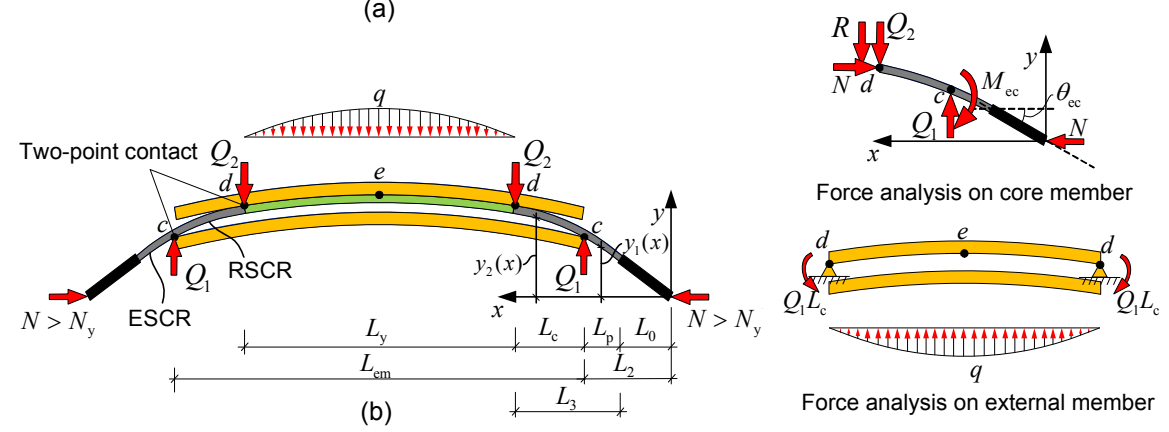

Fig. 2 Simplified force analysis for BRB with core single-wave deformation (a) Initial working status; (b) Working status 


\section{FE verification for the BRB with core single-wave overall deformation}

\subsection{FE model}

This section applies the universal FE software ABAQUS to establish six BRB models to verify the theoretically derived results from Part I (Jiang et al., 2015) (Fig. 3).

In the models, the 8-node linear brick with reduced integration (C3D8R) element is used to simulate the core member, external member, and stopper. The pinned connector, core member, and stopper are a whole, thus their contact surface is set with the tie constraint. In addition, the contact pair is established between the core and the external member, as well as the stopper and the hole at mid-span of the external member, and the friction between the contact pair is not considered. A steel plate with yield strength of $235 \mathrm{MPa}$ is used to model the core, and the tangent modulus in the plastic stage is set to be $2 \%$ of the elasticity modulus. The elastic-perfectly plastic material with yield strength of $345 \mathrm{MPa}$ is assumed for the external member. The elasticity modulus of the core and the external member is $206 \mathrm{GPa}$.

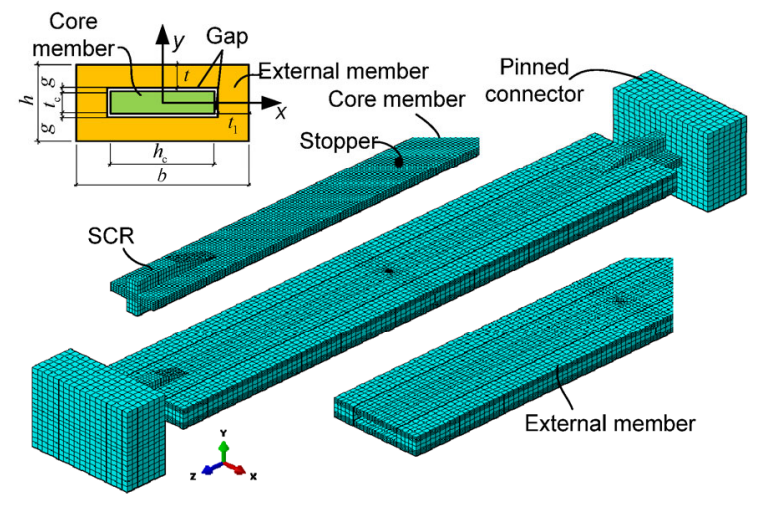

Fig. 3 BRB refined FE model
The pinned boundary is applied at the midline of a rigid pinned connector, and its rotation direction is consistent with that of the weak axis of the core flat-plate. In addition, axial displacement is applied, so as to simulate the pure pressure loading of the BRB. Since we are concerned with the revolving of the core member only around the $x$ axis, the displacement of the core member along the $x$ axis is fixed. The full Newton-RaPhson method is adopted for the solution, and the maximum and minimum increment sizes of the analysis step are set as 0.005 and $1 \times 10^{-10}$, respectively.

Core dimensions $\left(h_{\mathrm{c}} \times t_{\mathrm{c}}\right)$ of six BRBs are $160 \mathrm{~mm} \times 30 \mathrm{~mm}$; the external member width $b$ is $304 \mathrm{~mm}$; the flange thickness $t$ is $20 \mathrm{~mm}$; the web thickness $t_{1}$ is $70 \mathrm{~mm}$; the section dimensions $\left(b_{0} \times t_{0}\right)$ of the SCR are $50 \mathrm{~mm} \times 40 \mathrm{~mm}$. In the numerical analysis, the initial geometric imperfection with the amplitude of $\delta_{0}$ is applied to the external member, and the core single-wave imperfection mode is obtained from the modal analysis; other relevant geometric parameters are shown in Table 1, and their meanings are shown in Fig. 2. The restraining ratio $\xi$ (Black et al., 2004; Guo and Jiang, 2010) in Table 1 can be calculated by Eq. (5).

\subsection{FE analysis results}

Fig. 4 presents the $\mathrm{FE}$ analysis results of the BRB of MS-2 when the core axial strain is $3 \%$. Fig. 4a shows the lateral deformation of the core. In such a case, core single-wave overall deformation occurs and the corresponding core contact force distribution is shown in Fig. 4b. It shows that the core has two-point-contact with the external member at the end, and the end contact force $Q_{1}$ is larger than the contact force $Q_{2}$. In addition, the contact force distribution of the core contact region can be deemed sinusoidal. Fig. 4c and Fig. 4d respectively present

Table 1 Geometric parameters of BRB models (unit: $\mathbf{m m}$ )

\begin{tabular}{cccccccccccc}
\hline Model & $\xi$ & $L_{\mathrm{BRB}}$ & $L_{0}$ & $L_{\mathrm{cm}}$ & $L_{\mathrm{em}}$ & $L_{\mathrm{y} 0}$ & $L_{\mathrm{p} 0}$ & $L_{\mathrm{c} 10}$ & $L_{\mathrm{c} 20}$ & $g$ & $\delta_{0}$ \\
\hline MS-1 & 3.75 & 2080 & 40 & 2000 & 1920 & 1600 & 40 & 60 & 100 & 1 & 4 \\
MS-2 & 3.12 & 2280 & 140 & 2000 & 1820 & 1500 & 90 & 60 & 100 & 1 & 4 \\
MS-3 & 3.12 & 2280 & 140 & 2000 & 1820 & 1400 & 90 & 60 & 150 & 1 & 4 \\
MS-4 & 2.64 & 2480 & 240 & 2000 & 1920 & 1400 & 40 & 110 & 150 & 1 & 4 \\
MS-5 & 3.37 & 2280 & 140 & 2000 & 1920 & 1600 & 40 & 60 & 100 & 2 & 4 \\
MS-6 & 3.37 & 2280 & 140 & 2000 & 1820 & 1400 & 90 & 60 & 150 & 2 & 2 \\
\hline
\end{tabular}

Note: $L_{\mathrm{y} 0}, L_{\mathrm{p} 0}, L_{\mathrm{c} 10}$, and $L_{\mathrm{c} 20}$ represent the geometric dimensions when the BRB is in the initial state and the corresponding geometric parameters $\left(L_{\mathrm{y}}, L_{\mathrm{p}}\right.$, and $\left.L_{\mathrm{c}}\right)$ in the working state will gradually change with the core axial strain 
the bending moment distribution of the core and the external member; Fig. $4 \mathrm{c}$ verifies the assumption that the bending moment of the core contact region is zero in the simplified model.
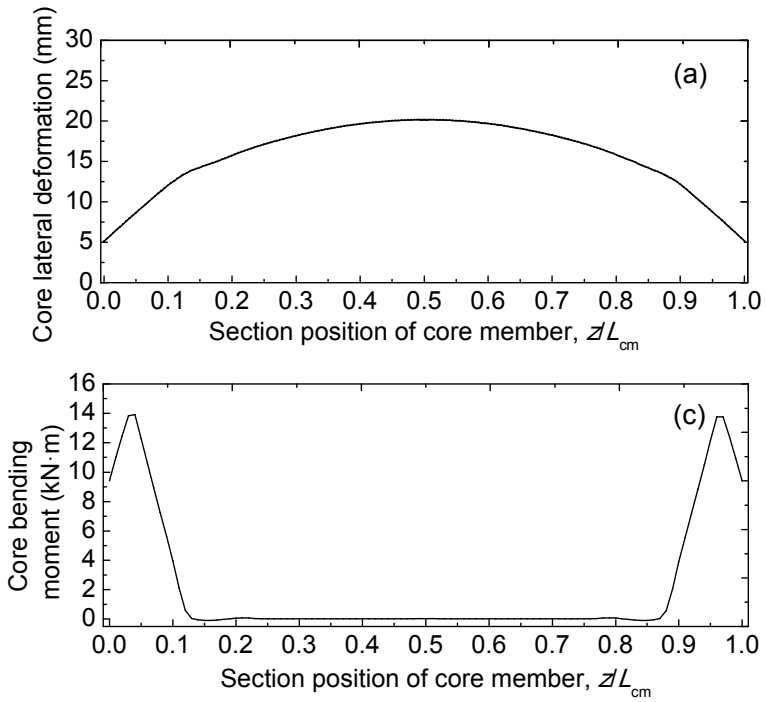

The FE analysis results shown in Fig. 5 denote that the maximum bending moment $M_{\mathrm{ec}}$ (Eq. (1)) of ESCR, the core end contact force $Q_{1}$ (Eq. (2)), the maximum bending moment $M_{\mathrm{em} \text {,max }}$ (Eq. (3)) of the
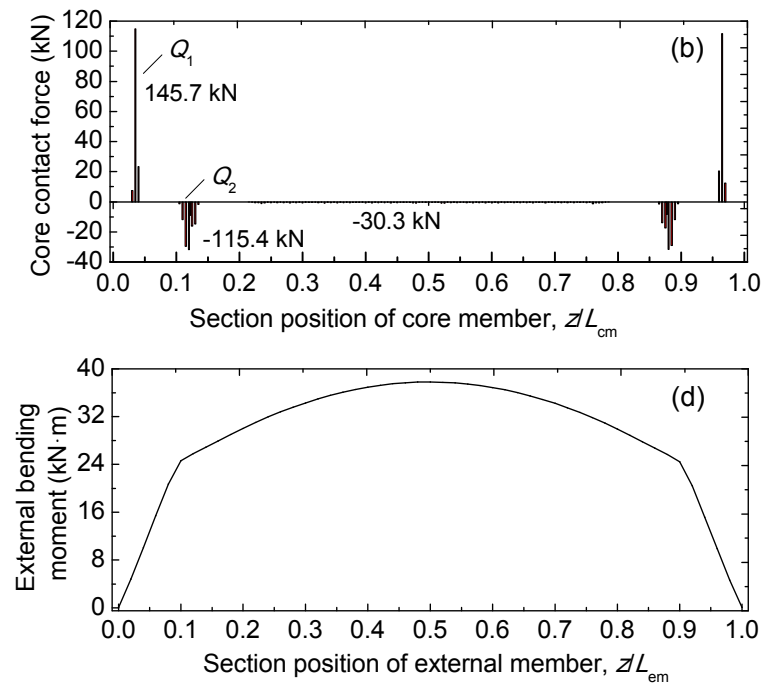

Fig. 4 FE analysis results of MS-2 BRB (3.0\% strain)

(a) Core lateral deformation; (b) Core contact force distribution; (c) Core bending moment distribution; (d) External member bending moment distribution

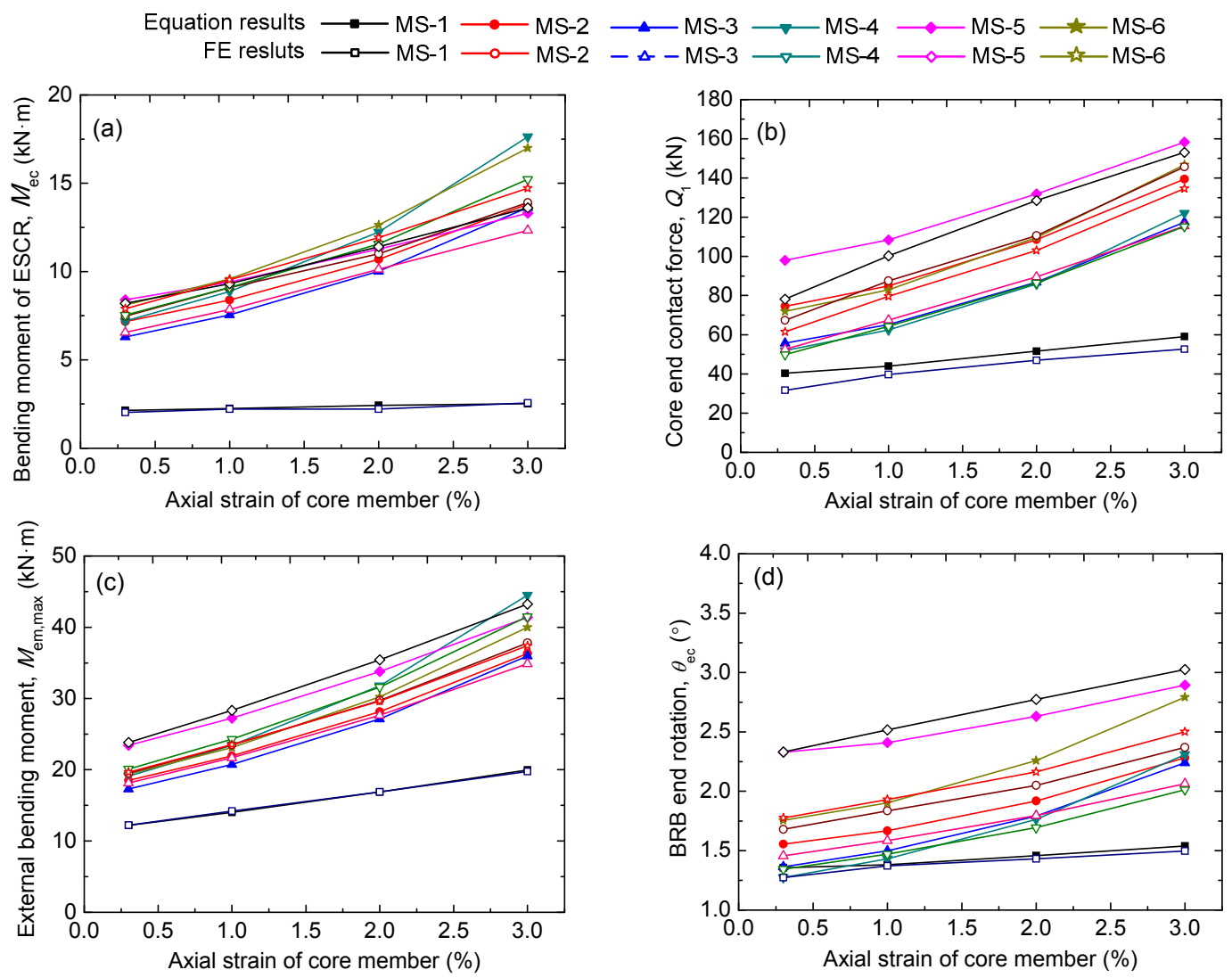

Fig. 5 FE verificaion of BRB with core single-wave deformation

(a)-(d) Rationality verification of Eqs. (1)-(4) 
external member, and the end rotation $\theta_{\mathrm{ec}}$ of BRB (Eq. (4)) match well with the FE analysis results. When the core axial strain is $3 \%$, the equation errors can be controlled within $10 \%$, thus meeting the engineering requirements. Also, it indicates that the basic assumptions and results in the previous theoretical derivation section are accurate.

Note that the equation derivation is obtained based on a small deformation assumption. When the external member yields or bending failure happens to the ESCR, large lateral deformation of the BRB occurs, and the calculated results become inaccurate.

\subsection{Parameter analysis}

To examine the accuracy of Eqs. (1)-(4), some parameter analyses are also made. The influence of nine design parameters, including the external member's flexural rigidity, gap, core thickness and its width-to-thickness ratio, pinned connector length, external member's initial imperfection, external member length, RSCR length with uniform section, and height of wing-plate of the SCR, on the core end contact force and the maximum bending moment of external member are examined, as shown in Fig. 6. The parameter analysis is based on the MS-2 model, and each group of analyses contains only one variable.

The analysis results show that the external member's flexural rigidity, gap, core thickness, core width-to-thickness ratio, and the pinned connector length will directly influence the restraining ratio of the BRBs. Increasing the external member's flange thickness can effectively improve the external member's flexural rigidity and reduce the core contact force. When the flange thickness $t>16 \mathrm{~mm}(\xi>2.15)$, its influence will be less significant. However, when the external member's rigidity becomes smaller $(t=14 \mathrm{~mm})$, the BRB will lose its axial load-bearing capacity, as shown in Fig. 6a. The change of the core end contact force and the maximum bending moment of the external member are linearly positively correlated with the change of gap (Fig. 6b). Thus, a smaller gap is suggested in BRB design. The core thickness change will directly influence the axial loadbearing capacity of the BRB. In addition, a thicker core leads to larger flexural rigidity of the external member when its flange thickness and the gap are unchanged. Accordingly, with the core thickness increasing, the restraining ratio may first become smaller and then larger. However, the core contact force and the external member's maximum bending moment show an approximately linear increase, as shown in Fig. 6c. Fig. 6d shows that, with increasing core width-to-thickness ratio, the increase of the core contact force and the maximum bending moment of the external member will become moderate gradually. Note that when the external member materials are the same, the BRB with larger core width-tothickness ratio possesses lower external member bending efficiency. The length of the pinned connector is mainly related to the end construction of the BRB. When increasing the pinned connector length, the stress level of the external member becomes unfavorable and the ESCR is easily damaged by bending. For instance, when $L_{0}>220 \mathrm{~mm}$, the gradient of the curve changes (Fig. 6e). In such a case, bending failure occurs at the SCR.

Different BRBs may have the same restraining ratio, but their performance may differ hugely. For instance, for BRB $\xi=3.00$ in Fig. 6 b, its performance is much better than that of the BRB $\xi=3.02$ in Fig. 6e.
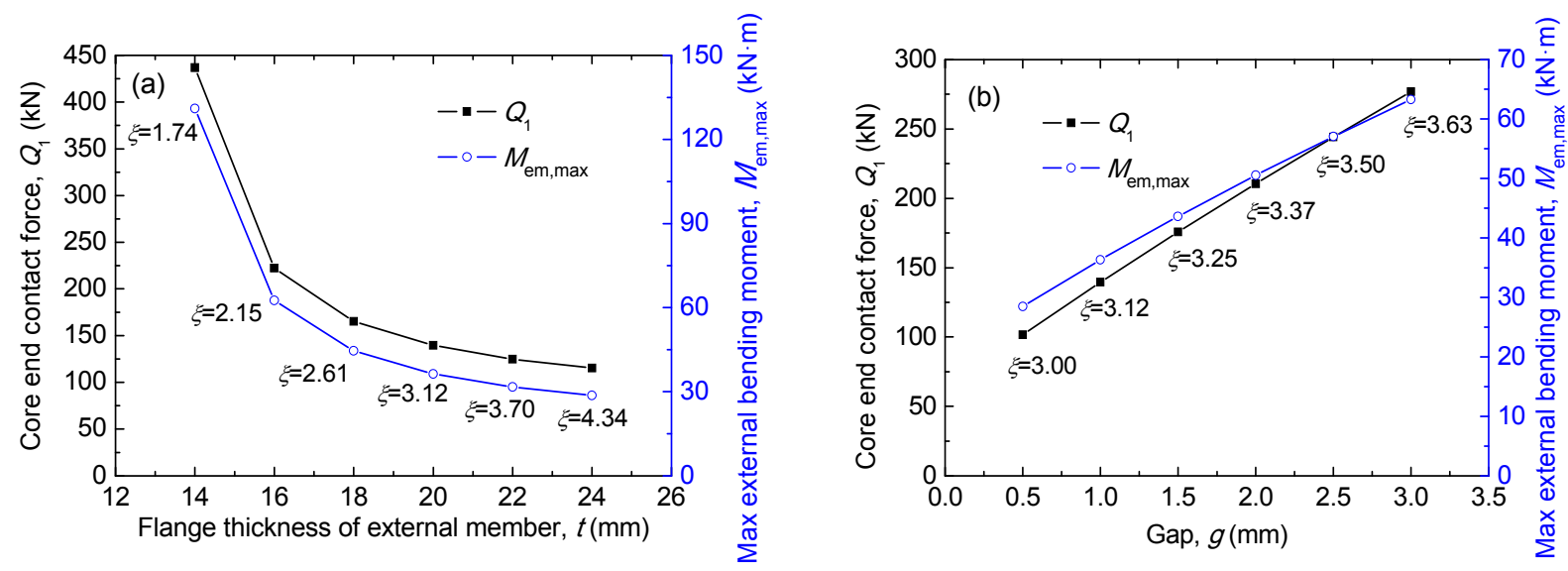

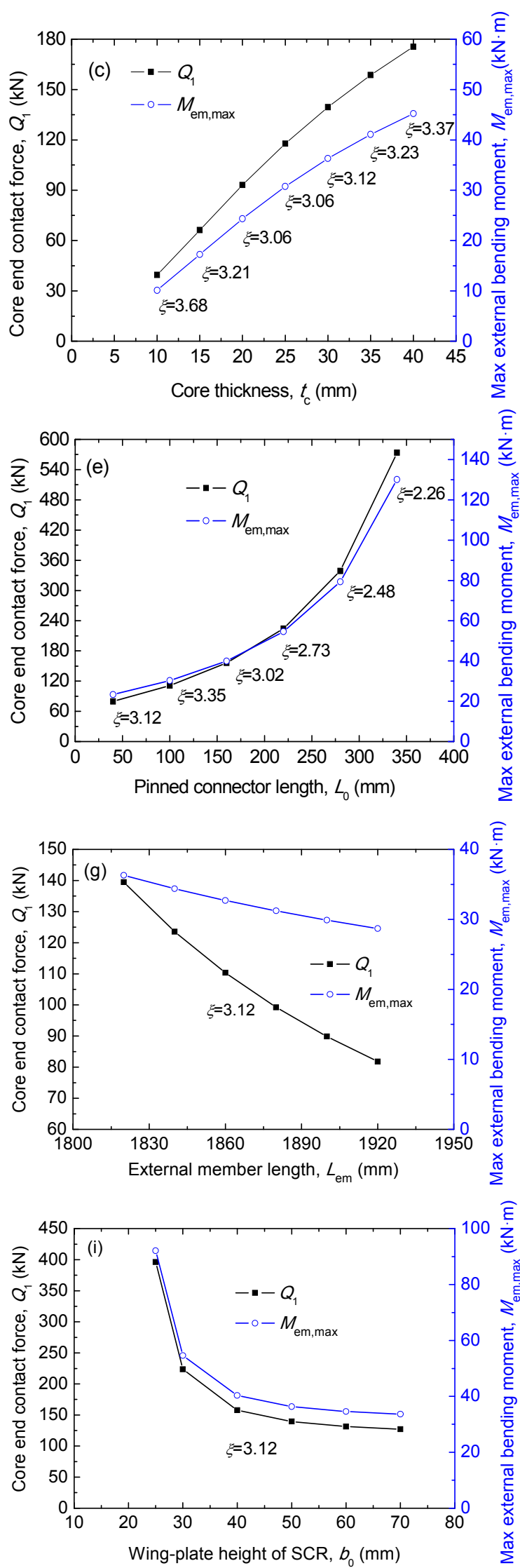
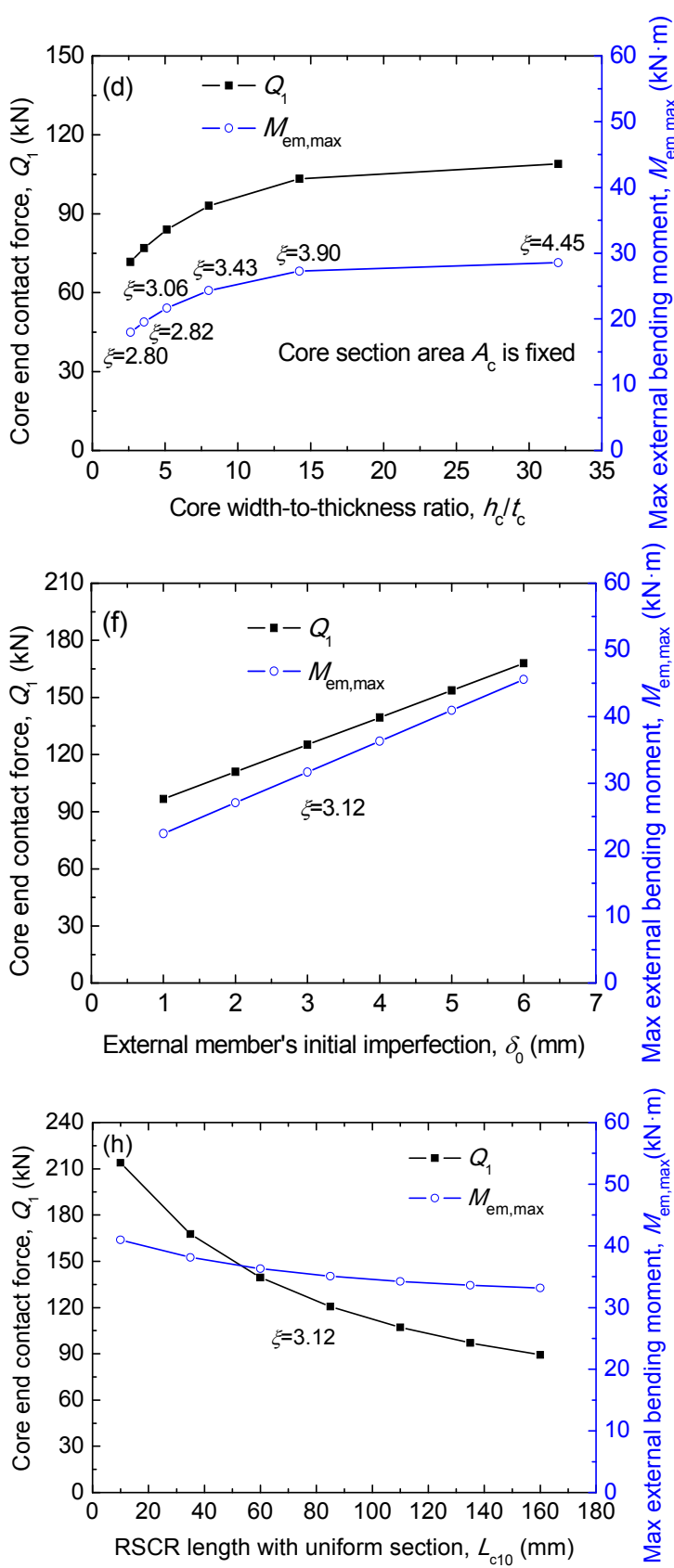

Fig. 6 Parameter analysis results of MS-2 BRB with core single-wave deformation

(a) Influence of external member's flange thickness $t$; (b) Influence of the gap $g$; (c) Influence of core thickness $t_{\mathrm{c}}$; (d) Influence of core width-to-thickness ratio $h_{\mathrm{c}} / t_{\mathrm{c}}$; (e) Influence of the pinned connector length $L_{0}$; (f) Influence of external member's initial imperfection $\delta_{0}$; (g) Influence of external member length $L_{\mathrm{em}}$; (h) Influence of the RSCR length with uniform section $L_{\mathrm{c} 10}$; (i) Influence of the height of wingplate of SCR $b_{0}$ 
In addition, variation of design parameters, including the external member's initial imperfection, external member length, RSCR length with uniform section, and height of wing-plate of the SCR, cannot be reflected in the restraining ratio, but they can still directly influence the BRB's performance.

The core contact force and the external member's maximum bending moment have a linearly positive correlation with the initial imperfection of the external member (Fig. 6f). Thus, it is necessary to control the initial geometric imperfection in BRB manufacture. The external member length will directly influence the RSCR length with uniform section and is linearly negatively correlated with the core contact force and the external member's maximum bending moment (Fig. 6g). The increasing RSCR length with uniform section can also effectively improve BRB mechanical performance, and especially it can reduce the core end contact force (Fig. 6h). Increasing height of wing-plate of the SCR can effectively improve the axial rigidity and flexural rigidity of the ESCR as well as prevent bending failure in the ESCR (Fig. 6i). For example, a BRB with $b_{0}=30 \mathrm{~mm}$ will suffer bending damage at the SCR.

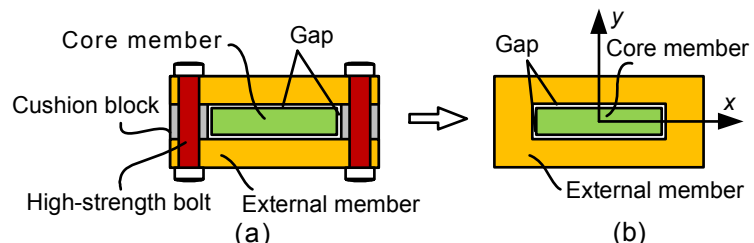

(a)

(b)

Fig. 7 BRB Section-1 (S1)

(a) Assembled BRB; (b) Integrated BRB

\section{Verification for BRB design method}

\subsection{FE model}

The above design method of the BRB is applicable for BRBs with different external member section forms. In this section, twelve BRBs are applied to check the reliability of the above design equations, where two different types of external member section forms are investigated, as shown in Figs. 7 and 8. For the assembled BRB, when connecting bolts' layout is dense, the assembled external member can be considered as the externally integrated BRB.

As mentioned above, the FE software ABAQUS is applied to establish the BRB models. The model settings and material characteristics of the BRB are the same as those in Section 3.1. The geometric parameters of the BRBs are shown in Table 2: the core width $h_{\mathrm{c}}$ of all BRBs is $160 \mathrm{~mm}$, the external member width $b$ is $304 \mathrm{~mm}$, web thickness $t_{1}$ is $70 \mathrm{~mm}$; the section dimensions of the external channel $\left(h_{1} \times b_{1} \times d_{1} \times t_{1}\right)$ are $160 \mathrm{~mm} \times 50 \mathrm{~mm} \times 6.5 \mathrm{~mm} \times 10 \mathrm{~mm}$. Design parameters are changed, including the core length $L_{\mathrm{cm}}(2 \mathrm{~m}-4 \mathrm{~m})$, core thickness $t_{\mathrm{c}}(20 \mathrm{~mm}-$ $40 \mathrm{~mm}$ ), section dimensions of the SCR $b_{0} \times t_{0}$, gap $g$ (1 mm-2 mm), initial imperfection amplitude of the

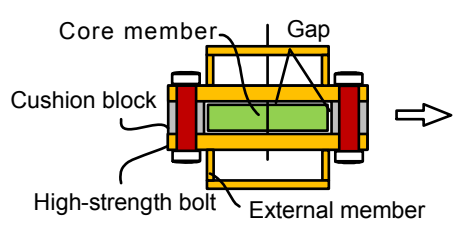

(a)

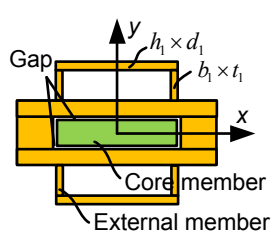

(b)
Fig. 8 BRB Section-2 (S2)

(a) Assembled BRB; (b) Integrated BRB

Table 2 Geometric parameters of BRB models (checking design equations) (unit: $\mathbf{m m}$ )

\begin{tabular}{cccccccccccccccc}
\hline Model name & $\xi$ & $L_{\mathrm{BRB}}$ & $L_{0}$ & $L_{\mathrm{cm}}$ & $L_{\mathrm{em}}$ & $L_{\mathrm{y} 0}$ & $L_{\mathrm{p} 0}$ & $L_{\mathrm{c} 10}$ & $L_{\mathrm{c} 20}$ & $t_{\mathrm{c}}$ & $t_{2}$ & $b_{0}$ & $t_{0}$ & $g$ & $\delta_{0}$ \\
\hline S1-MC-1 & 2.20 & 2480 & 240 & 2000 & 1920 & 1600 & 40 & 60 & 100 & 30 & 18.0 & 60 & 40 & 1 & $L_{\mathrm{em}} / 500$ \\
S1-MC-2 & 2.15 & 2280 & 140 & 2000 & 1820 & 1500 & 90 & 60 & 100 & 30 & 16.0 & 60 & 40 & 1 & $L_{\mathrm{em}} / 500$ \\
S1-MC-3 & 2.83 & 2280 & 140 & 2000 & 1820 & 1400 & 90 & 60 & 150 & 30 & 18.0 & 60 & 40 & 2 & $L_{\mathrm{em}} / 500$ \\
S1-MC-4 & 1.94 & 2280 & 140 & 2000 & 1880 & 1400 & 60 & 90 & 150 & 30 & 15.0 & 50 & 40 & 1 & $L_{\mathrm{em}} / 500$ \\
S1-MC-5 & 1.79 & 2480 & 240 & 2000 & 1920 & 1400 & 40 & 110 & 150 & 20 & 16.5 & 50 & 40 & 1 & $L_{\mathrm{em}} / 1000$ \\
S1-MC-6 & 2.59 & 2480 & 240 & 2000 & 1920 & 1400 & 40 & 110 & 150 & 20 & 20.0 & 50 & 30 & 1 & 0 \\
S1-MC-7 & 2.59 & 2480 & 240 & 2000 & 1860 & 1400 & 70 & 80 & 150 & 20 & 20.0 & 45 & 30 & 1 & $L_{\mathrm{em}} / 500$ \\
S1-MC-8 & 1.84 & 3500 & 250 & 3000 & 2870 & 2500 & 65 & 85 & 100 & 30 & 24.0 & 50 & 40 & 1 & $L_{\mathrm{em}} / 500$ \\
S1-MC-9 & 1.62 & 4500 & 250 & 4000 & 3840 & 3400 & 80 & 70 & 150 & 40 & 29.0 & 70 & 50 & 1 & $L_{\mathrm{em}} / 1000$ \\
S1-MC-10 & 1.84 & 4500 & 250 & 4000 & 3840 & 3500 & 80 & 70 & 100 & 20 & 29.0 & 50 & 40 & 2 & $L_{\mathrm{em}} / 1000$ \\
S2-MC-11 & 5.62 & 2480 & 240 & 2000 & 1920 & 1400 & 40 & 110 & 150 & 30 & 10.0 & 50 & 40 & 2 & $L_{\mathrm{em}} / 500$ \\
S2-MC-12 & 2.85 & 3480 & 240 & 3000 & 2890 & 2400 & 55 & 95 & 150 & 30 & 10.0 & 50 & 40 & 2 & $L_{\mathrm{em}} / 500$ \\
\hline
\end{tabular}


external member $\delta_{0}$, pinned connector length $L_{0}$, and flange thickness of the external member $t_{2}$.

The aforementioned equations are applied to check these BRBs, and the results of BRBs when the core strain is $3 \%$ are presented in Table 3 . Table 3 shows that the bending capacity of the external member of BRBs MC-4, MC-5, MC-8, and MC-9 cannot meet the requirements of the proposed strength design equation (Eq. (6)). Moreover, the ESCR of BRBs MC-4, MC-5, MC-7, MC-8, MC-10, MC-11, and MC-12 may suffer bending damage as they cannot meet the design requirement (Eq. (7)). Fig. 9 shows the check results of the ESCR. Whether or not BRBs meet the design requirement can be judged from this figure. The curve represents the checking equation of the ESCR and the points show the internal force of the ESCR of each BRB when the core strain is $3 \%$. If the BRB is up to the design requirements (Eq. (7)), the corresponding point representing the ESCR force state will be within the

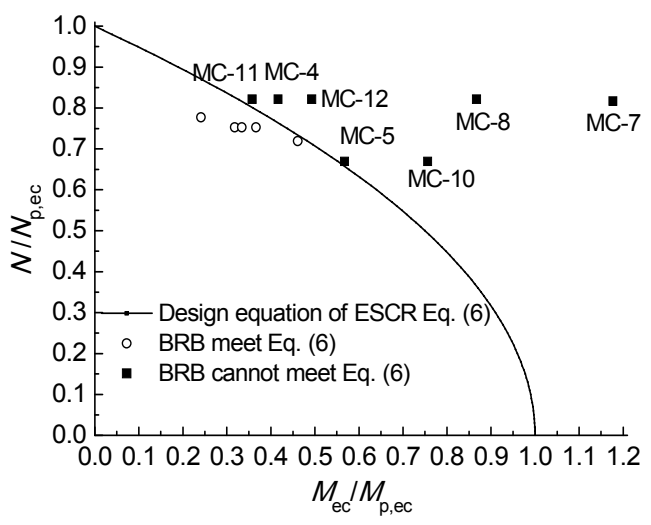

Fig. 9 ESCR design check area enveloped by the horizontal and vertical axes and the curve; otherwise, it will be out of the curve.

\subsection{Verification for design method}

Figs. 10 and 11 respectively present the axial strain vs. axial force curves of the BRBs, the axial strain vs. the core member mid-span nodal lateral displacement curves, as well as the axial strain vs. the BRB rotation curves of MC1-MC6 and MC7MC12. In Figs. 10 and $11, f_{\text {cy }}$ is the core yield strength, and $A_{\mathrm{c}}$ is the section areas of the core flatplate. Figs. 10 and 11 show that the BRBs of MC-7, MC-8, MC-9, and MC-12 all lose axial load-bearing capacity. The $\mathrm{BRB}$ of $\mathrm{MC}-7$ has bending failure in the ESCR (Fig. 12), and the core lateral deformation shows a non-linear increase. While the MC-9 fails, the core lateral deformation and the end rotation have a sharp increase due to insufficient bearing capacity of the external member (Fig. 13, p.803).

The FE analysis results show that the BRBs of MC-4 and MC-5 still possess stable axial loadbearing capacity, and $M_{\mathrm{em} \text {,max }}$ solved by Eq. (3) is slightly larger than the bending capacity $M_{\mathrm{em}, \mathrm{u}}$ of the external member, indicating that the design equation of the external member is sufficiently conservative. In addition, with the application of a rectangular section plastic design method, enough safety margin can be ensured when the SCR with cruciform section is checked by Eq. (7). For instance, Eq. (7) predicts that the core end of the BRB of MC-10 will have end bending failure, but the $\mathrm{FE}$ analysis result shows that it still has stabilized axial load-bearing capacity, and the failure tendency does exist, as shown in Fig. 11b.

Table 3 Equation results of BRB model (strain 3\%)

\begin{tabular}{cccccccccccc}
\hline Model & $\begin{array}{c}Q_{1} \\
(\mathrm{kN})\end{array}$ & $\begin{array}{c}M_{\mathrm{em}, \max } \\
(\mathrm{kN} \cdot \mathrm{m})\end{array}$ & $\begin{array}{c}\theta_{\mathrm{ec}} \\
\left({ }^{\circ}\right)\end{array}$ & $\begin{array}{c}N \\
(\mathrm{kN})\end{array}$ & $\begin{array}{c}N_{\mathrm{p}, \mathrm{ec}} \\
(\mathrm{kN})\end{array}$ & $\begin{array}{c}M_{\mathrm{ec}} \\
(\mathrm{kN} \cdot \mathrm{m})\end{array}$ & $\begin{array}{c}M_{\mathrm{p}, \mathrm{ec}} \\
(\mathrm{kN} \cdot \mathrm{m})\end{array}$ & $\begin{array}{c}M_{\mathrm{em}, \mathrm{u}} \\
(\mathrm{kN} \cdot \mathrm{m})\end{array}$ & Eq. (7) & $\xi$ & {$[\xi]$} \\
\hline S1-MC-1 & 207.4 & 57.3 & 2.86 & 1699 & 2256 & 21.7 & 59.2 & 76.3 & 0.93 & 2.20 & 1.40 \\
S1-MC-2 & 195.4 & 55.2 & 3.09 & 1699 & 2256 & 18.8 & 59.2 & 66.8 & 0.88 & 2.15 & 1.58 \\
S1-MC-3 & 177.7 & 52.5 & 3.24 & 1699 & 2256 & 19.8 & 59.2 & 80.4 & 0.90 & 2.83 & 1.28 \\
S1-MC-4 & 171.4 & 66.5 & 3.65 & 1699 & 2068 & 19.2 & 46.1 & 62.2 & 1.09 & 1.94 & 2.25 \\
S1-MC-5 & 145.9 & 55.7 & 4.08 & 1132 & 1692 & 20.8 & 36.7 & 51.1 & 1.02 & 1.79 & 2.25 \\
S1-MC-6 & 46.2 & 15.0 & 1.35 & 1132 & 1457 & 6.9 & 28.4 & 65.6 & 0.85 & 2.59 & 0.62 \\
S1-MC-7 & 182.0 & 55.4 & 5.08 & 1132 & 1387 & 28.7 & 24.4 & 65.6 & 1.84 & 2.59 & 1.64 \\
S1-MC-8 & 312.0 & 129.5 & 4.87 & 1699 & 2068 & 39.9 & 46.1 & 108.0 & 1.54 & 1.84 & 2.48 \\
S1-MC-9 & 357.4 & 214.7 & 4.42 & 2265 & 3149 & 48.6 & 105.5 & 167.8 & 0.98 & 1.62 & 2.12 \\
S1-MC-10 & 218.7 & 101.3 & 5.06 & 1132 & 1692 & 27.7 & 36.7 & 115.9 & 1.20 & 1.84 & 1.63 \\
S2-MC-11 & 113.8 & 36.4 & 2.16 & 1699 & 2068 & 16.5 & 46.1 & 85.9 & 1.03 & 5.62 & 0.85 \\
S2-MC-12 & 157.6 & 65.5 & 2.97 & 1699 & 2068 & 22.7 & 46.1 & 85.9 & 1.17 & 2.85 & 1.73 \\
\hline
\end{tabular}



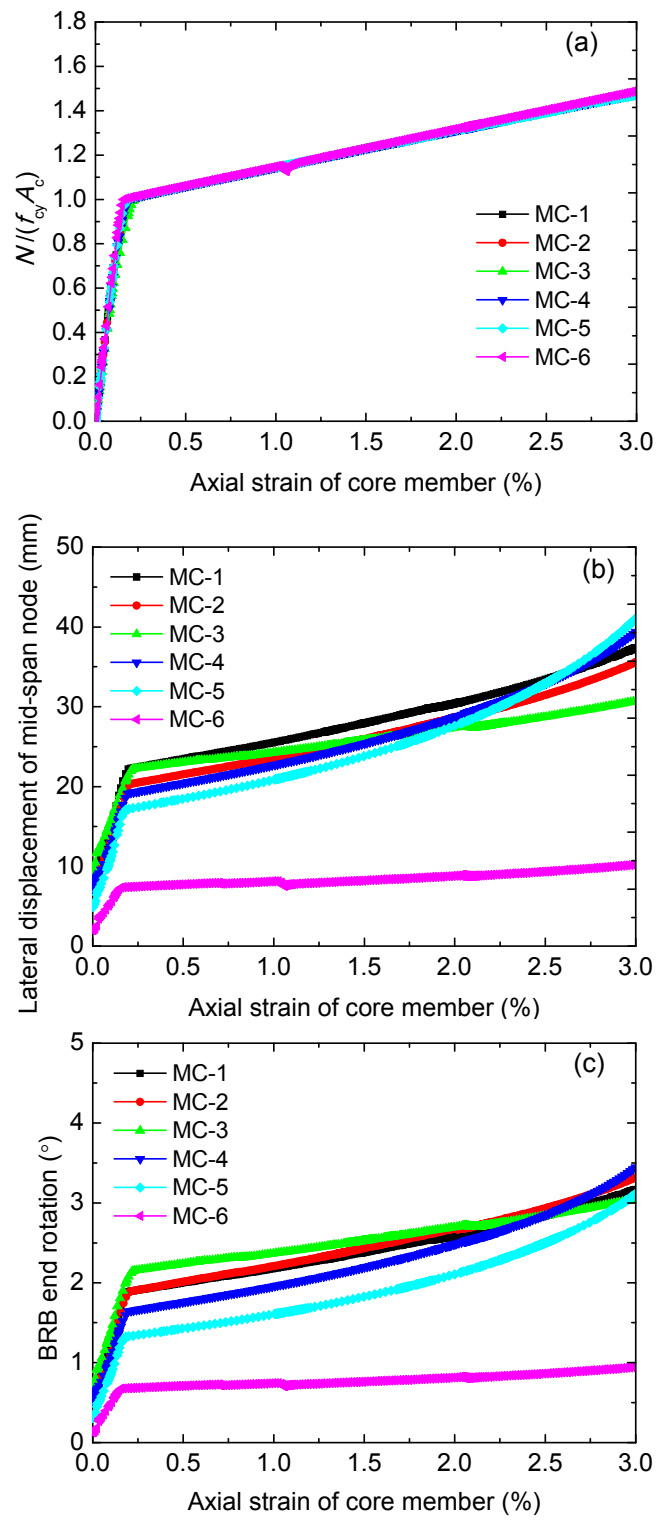

Fig. 10 Core axial strain vs. relevant parameter curves of MC1-MC6

(a) Core axial strain vs. axial force; (b) Core axial strain vs. lateral displacement; (c) Core axial strain vs. end rotation
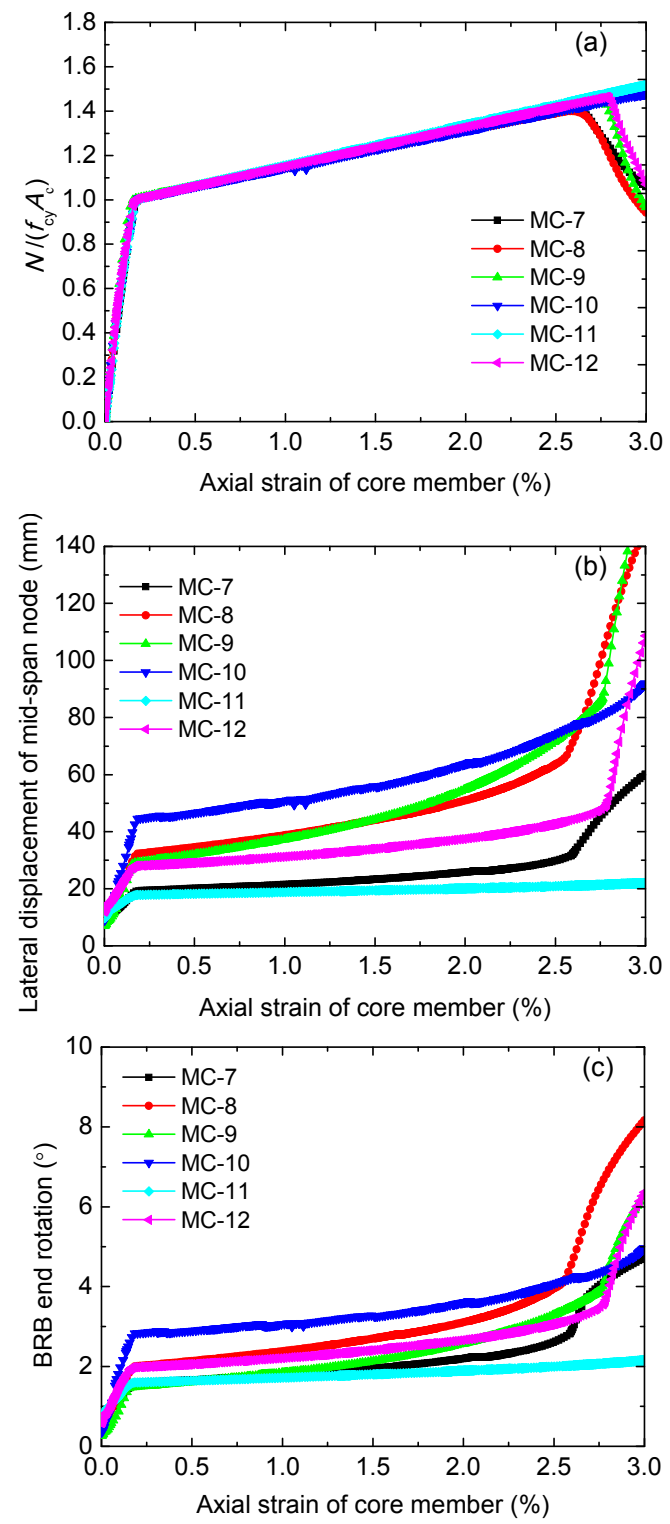

Fig. 11 Core axial strain vs. relevant parameter curves of MC7-MC12

(a) Core axial strain vs. axial force; (b) Core axial strain vs. lateral displacement; (c) Core axial strain vs. end rotation

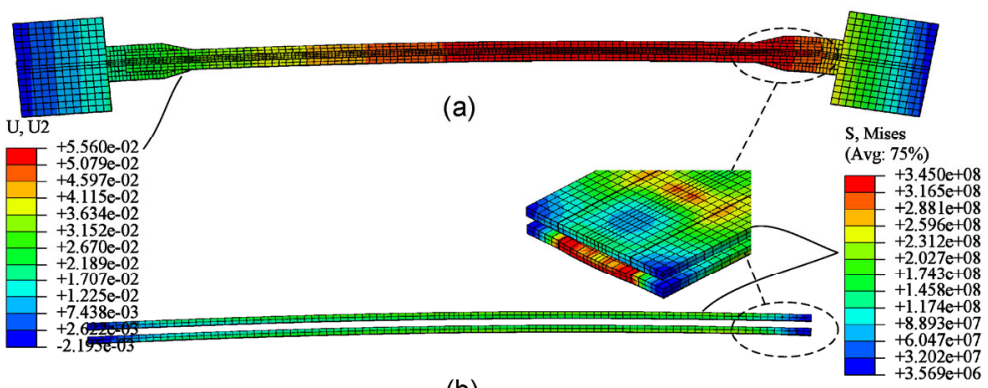

(b)

Fig. 12 FE analysis result of the BRB of MC-7

(a) Lateral deformation of BRB; (b) The von Mises stress of external members' flanges 


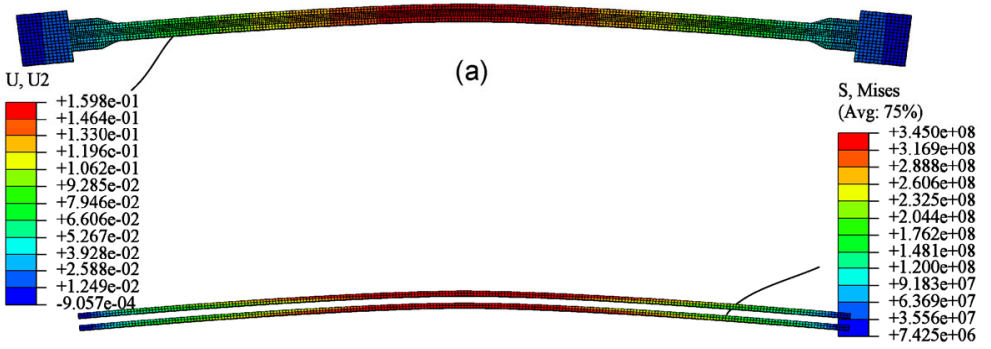

(b)

Fig. 13 FE analysis result of the BRB of MC-9

(a) Lateral deformation of BRB; (b) The von Mises stress of external members' flanges

Generally speaking, the theoretical analysis results are consistent with the FE results, which are safe and meet the engineering design requirements.

\section{Conclusions}

This study presents an FE numerical verification of the Part I paper (Jiang et al., 2015). FE analysis is applied to: (1) verify the theoretical assumptions and results of Part I, as well as the accuracy and feasibility of the equations derived theoretically; (2) quantify the influence of nine parameters on the pinned BRBs' performance; (3) check the proposed strength design method of the pinned BRBs. The following conclusions are obtained:

1. FE numerical results indicate that the basic assumptions and equation derivation in the theoretical analysis of Part I are accurate, and the proposed design method of the pinned BRBs can precisely predict the BRB's overall buckling failure and bending failure in the ECSR of BRBs.

2. As the design of the external member and the strengthened core region directly affect the failure modes of the pinned BRBs, both sufficient rigidity and strength for the external member and the SCR are required.

3. Although the design parameters such as the external member's initial imperfection, external member length, the RSCR length with uniform section, and the height of wing-plate of SCR cannot be reflected directly in the restraining ratio, these parameters can be all considered in the proposed design method of the pinned BRBs.

4. Considering the significant influence of the gap, the core width-to-thickness ratio, and the external member's initial imperfection on the core contact force acting on the external member, these parameters should be well controlled while designing them. It is also concluded that a shorter pinned connector, a relatively long external member and the RSCR with uniform section are favorable in designing a pinned $\mathrm{BRB}$, because they can minimize the core contact force and the maximum bending moment of the external member.

\section{References}

Black, C.J., Makris, N., Aiken, I.D., 2004. Component testing, seismic evaluation and characterization of bucklingrestrained braces. Journal of Structural Engineering, ASCE, 130(6):880-894. [doi:10.1061/(ASCE)0733-9445 (2004)130:6(880)]

Chen, C.C., Chen, S.Y., Liaw, J.J., 2001. Application of low yield strength steel on controlled plastification ductile concentrically braced frames. Canadian Journal of Civil Engineering, 28(5):823-836. [doi:10.1139/101-044]

Chen, J., 2005. Principles of Steel Structure Design. Science Press, Beijing, p.210-213 (in Chinese).

Chou, C., Chen, S., 2010. Subassemblage tests and finite element analyses of sandwiched buckling-restrained braces. Engineering Structures, 32(8):2108-2121. [doi:10.1016/j.engstruct.2010.03.014]

Di Sarno, L., Manfredi, G., 2010. Seismic retrofitting with buckling restrained braces: application to an existing non-ductile RC framed building. Soil Dynamics and Earthquake Engineering, 30(11):1279-1297. [doi:10. 1016/j.soildyn.2010.06.001]

Di Sarno, L., Manfredi, G., 2012. Experimental tests on fullscale RC unretrofitted frame and retrofitted with buckling restrained braces. Earthquake Engineering and Structural Dynamics, 41(2):315-333. [doi:10.1002/eqe. 1131]

Di Sarno, L., Chiodi, R., Manfredi, G., et al., 2013. Probabilistic assessment of seismic behaviour of an existing RC building retrofitted with BRBs. Proceedings of the 11th International Conference on Structural Safety \& Reliability (ICOSSAR), New York, USA. 
Fahnestock, L.A., Ricles, J.M., Sause, R., 2007. Experimental evaluation of a large-scale buckling-restrained braced frame. Journal of Structural Engineering, ASCE, 133(9): 1205-1214. [doi:10.1061/(ASCE)0733-9445(2007)133: 9(1205)]

Guo, Y.L., Jiang, L.X., 2010. Behavior and application of buckling-restrained braces assembled with section steels. Building Structure, 40(1):30-37 (in Chinese).

Inoue, K., Sawaisumi, S., 1992. Bracing design criterion of the reinforced concrete panel including unbonded steel diagonal braces. Journal of Structural and Construction Engineering, 432(3):41-49 (in Japanese).

Iwata, M., Murai, M., 2006. Buckling-restrained brace using steel mortar planks; performance evaluation as a hysteretic damper. Earthquake Engineering \& Structural Dynamics, 35(14):1807-1818. [doi:10.1002/eqe.608]

Jiang, Z.Q., Guo, Y.L., Wang, X.A., et al., 2015. Design method of the pinned external integrated bucklingrestrained braces with extended core. Part I: theoretical derivation. Journal of Zhejiang University-SCIENCE A (Applied Physics \& Engineering), 16(10):781-792. [doi:10.1631/jzus.A1400325]

Ju, Y.K., Kim, M., Kim, J., et al., 2009. Component tests of buckling-restrained braces with unconstrained length. Engineering Structures, 31(2):507-516. [doi:10.1016/j. engstruct.2008.09.014]

Nagao, T., Takahashi, S., 1991. A study on the elasto-plastic behavior of unbonded composite bracing (Part 2: analytical studies). Journal of Structural Construction Engineering, 422(4):45-56 (in Japanese).

Qiang, X., 2005. Status of the art of buckling-restrained braces in Asia. Journal of Constructional Steel Research, 61(11):727-748.

Tremblay, R., Bolduc, P., Neville, R., et al., 2006. Seismic testing and performance of buckling-restrained bracing systems. Canadian Journal of Civil Engineering, 33(2): 183-198. [doi:10.1139/105-103]

Tsai, K., Hsiao, P., 2008. Pseudo-dynamic test of a full-scale CFT/BRB frame-Part II: seismic performance of buckling-restrained braces and connections. Earthquake Engineering \& Structural Dynamics, 37(7):1099-1115. [doi:10.1002/eqe.803]

Wigle, V.R., Fahnestock, L.A., 2010. Buckling-restrained braced frame connection performance. Journal of Constructional Steel Research, 66(1):65-74. [doi:10.1016/j. jcsr.2009.07.014]
Zhao, J., Wu, B., Ou, J., 2011. A novel type of angle steel buckling-restrained brace: cyclic behavior and failure mechanism. Earthquake Engineering \& Structural Dynamics, 40(10):1083-1102. [doi:10.1002/eqe.1071]

Zhao, J., Wu, B., Ou, J., 2012a. Effect of brace end rotation on the global buckling behavior of pin-connected buckling-restrained braces with end collars. Engineering Structures, 40(5):240-253. [doi:10.1016/j.engstruct.2012. 02.030]

Zhao, J., Wu, B., Ou, J., 2012b. Flexural demand on pinconnected buckling-restrained braces and design recommendations. Journal of Structural Engineering, ASCE, 138(11):1398-1415. [doi:10.1061/(ASCE)ST.1943-541X. 0000549]

\section{中文概要}

题 目: 内核外伸铰接防屈曲支撑设计理论研究. 第二部 分: 数值验证

目的: 本文旨在对系列文章第一部分所得到的理论推 导结果进行相应的有限元数值验证, 同时对内 核单波变形下的支撑构件进行参数分析。

方 法: 采用通用有限元软件 ABAQUS 建立六个防屈曲 支撑模型对内核单波变形下理论推导公式进行 校核; 并对理论公式进行参数分析, 考察外围 构件抗弯刚度、间隙大小、内核构件厚度、内 核构件宽厚比、铰接接头长度、外围约束构件 初始缺陷、外围构件长度、内核约束加强段长 度及内核加强段翼板高度等 9 个参数对内核挤压 力及外围构件受力影响; 最后通过对 12 个防屈 曲支撑进行数值模拟, 验证支撑设计理论的合 理性。

结 论: 该理论设计公式能较好地预测支撑的破坏情况 及内力发展情况, 具有较强的安全性和较广的 适用性, 为铰接防屈曲支撑的使用推广奠定理 论基础。

关键词: 防屈曲支撑; 内核单波整体变形; 挤压力分 布; 内核构件加强段; 设计准则; 精细有限元 